\title{
Modelling and simulation of a single slit micro packed bed reactor for methanol synthesis
}

\author{
Hamidreza Bakhtiary-Davijany ${ }^{\mathrm{a}, 1}$, Fatemeh Hayer $^{\mathrm{a}, 2}$, Xuyen Kim Phan ${ }^{\mathrm{a}, 3}$, Rune Myrstad ${ }^{\mathrm{b}}$, \\ Hilde J. Venvik ${ }^{\mathrm{a}, *}$, Peter Pfeifer ${ }^{\mathrm{c}}$, Anders Holmen ${ }^{\mathrm{a}, *}$ \\ ${ }^{a}$ Department of Chemical Engineering, Norwegian University of Science and Technology (NTNU), NO-7491 Trondheim, Norway \\ b SINTEF Materials and Chemistry, NO-7465, Trondheim, Norway \\ ${ }^{\mathrm{c}}$ Karlsruhe Institute of Technology (KIT), Institute for Micro Process Engineering, Hermann-von-Helmholtz-Platz 1, DE-76344 Eggenstein-Leopoldshafen, Germany
}

\section{A B S T R A C T}

A mathematical model for a single slit packed microstructured reactor-heat exchanger in the synthesis of methanol from syngas was developed. The model constitutes a simplified 3D-pseudo homogeneous approach for a reaction slit with integrated pillar geometry. Literature kinetic rate expressions for methanol synthesis over commercial Cu/ZnO/support type catalysts were applied at 80 bar total pressure, temperature range of $473-558 \mathrm{~K}$, and syngas composition of $\mathrm{H}_{2} / \mathrm{CO} / \mathrm{CO}_{2} / \mathrm{N}_{2}: 65 / 25 /$ $5 / 5 \mathrm{~mol} \%$. The model is found capable of predicting experimental CO conversion data with acceptable accuracy. Superior thermal stability of the microchannel upon variation of different parameters such as contact time, feed gas temperature and reaction temperature were shown. The simulation results also reveal that the microchannel reactor can operate free of performance loss due to concentrations field that may arise from overlaid temperature fields. Simulations have also been used to calculate the rapid temperature transients at the inlet. The agreement between simulation results and experimental data signifies the applicability of the developed model for further design and performance optimization of microstructured reactors for methanol synthesis and other exothermic processes.

\section{Introduction}

Microstructured reactors have received considerable attention within the area of process intensification and heterogeneous catalysis [1]. The application of these reactors is particularly relevant for systems where limitations in heat and mass transport apply [2]. With respect to highly exothermic reactions, partial oxidation of hydrocarbons $[3,4]$ and oxidation of sulfur dioxide $[5,6]$, as well as gas-to-liquid processes such as the Fischer-Tropsch $[7,8,9,10]$, methanol and direct DME syntheses $[11,12]$ are examples. For the latter two - equilibrium limited - syntheses, the prospect of a forced temperature profile to approach the maximum rate curve is another motivation for application of a highly effective heat removal reactor system.

Methanol synthesis from synthesis gas is a well-known catalytic process $[13,14,15]$. The synthesis gas is a mixture of $\mathrm{CO} / \mathrm{CO}_{2} / \mathrm{H}_{2}$ that reacts over a $\mathrm{Cu} / \mathrm{ZnO} / \mathrm{A}_{2} \mathrm{O}_{3}$ catalyst, typically at $200-270{ }^{\circ} \mathrm{C}$ and 50 100 bars. The process is limited by equilibrium and is usually described by three main reactions:

$\mathrm{CO}+2 \mathrm{H}_{2} \leftrightarrow \mathrm{CH}_{3} \mathrm{OH}$

$$
\left(\Delta \mathrm{H}_{298 \mathrm{~K}}=-90.7 \mathrm{~kJ} / \mathrm{mol}\right)
$$

$$
\begin{array}{ll}
\mathrm{CO}_{2}+3 \mathrm{H}_{2} \leftrightarrow \mathrm{CH}_{3} \mathrm{OH}+\mathrm{H}_{2} \mathrm{O} & \left(\Delta \mathrm{H}_{298 \mathrm{~K}}=-49.5 \mathrm{~kJ} / \mathrm{mol}\right) \\
\mathrm{CO}_{2}+\mathrm{H}_{2} \leftrightarrow \mathrm{CO}+\mathrm{H}_{2} \mathrm{O} & \left(\Delta \mathrm{H}_{298 \mathrm{~K}}=+41.2 \mathrm{~kJ} / \mathrm{mol}\right)
\end{array}
$$

A main design challenge in conventional technology for this system of reactions is efficient removal of the reaction heat. Quench or cooled multitubular reactors are therefore usually applied in commercial practice. Low conversion per single pass is, however, obtained due to the thermodynamic equilibrium limitation $[13,14]$. Due to this, development of catalysts active at low temperature has also been targeted, and the Cu-based catalyst was a major breakthrough in this respect [14]. Finally, the reaction is intra particle diffusion limited due to the catalyst pellet size required to minimize pressure drop in conventional reactors [16]. In view of this, application of microchannels with strongly enhanced heat and mass transfer could play an important role in obtaining a high reactor productivity.

The efficiency of heat removal in microstructured reactors is, however, affected by the concept of solid catalyst loading into the channels. For example, packed channels may provide less efficient heat removal as compared to wall-coated ones due to less contact area between the catalyst and the walls [4]. Since true catalyst temperature

\footnotetext{
* Corresponding authors.

E-mail addresses: Hilde.J.Venvik@ntnu.no (H.J. Venvik), Anders.Holmen@ntnu.no (A. Holmen).

${ }^{1}$ Present addresses: Cambi Group AS, Skysstasjon 11A, NO-1383 Asker, Norway.

${ }^{2}$ Aibel AS, Vestre Svanholm 14, NO-4066 Stavanger, Norway.

${ }^{3}$ ExperWell, Fabrikkvei 8, NO-4033 Stavanger, Norway.
} 
measurements are difficult $[11,17]$ the development of models to facilitate insight to the temperature distribution within the catalyst bed in microreactors is relevant. Such models could also be used to provide indepth understanding of reactor performance under different operating conditions and hence be applied for further improvement of heat and mass transfer. Flexibility in the design and up-scaling of microstructured reactors could be possible through applying such tuned models.

There are several publications on modeling and simulation of microchannels reactors for exothermic gas phase reactions over solid phase catalysts. Cao et al developed a heterogeneous reactor model for catalytic steam reforming of methane in microchannel reactors [18] and showed advanced heat and mass transport properties of the microstructured configurations. They also investigated Fischer-Tropsch synthesis in a microchannel reactor [19] and demonstrated capability of these reactors for improved heat removal and enhanced productivity with less selectivity to methane. Hayer et al. [17] applied a 2D-dispersion model to represent a micro-packed bed reactor for direct DME synthesis. They demonstrated superior heat removal capability of the reactor at typical operating conditions of a direct DME process. Nevertheless, modelling of methanol synthesis from synthesis gas in a microchannel reactor has, to the knowledge of the authors, not been reported in literature.

In previous publications we have performed experimental investigations on different aspects of methanol synthesis from synthesis gas in an Integrated Micro Packed Bed Reactor-Heat Exchanger (IMPBRHE) $[11,17,20]$. The purpose of this paper is to describe the advanced transfer characteristics of the IMPBRHE observed in the experimental work through a model that includes the main governing phenomena involved. Such a model can be used to highlight the potential technology benefits for process intensification purposes, and tuned for optimization of operating conditions, reactor productivity and design of a larger reactors.

\section{Modelling approach}

The experiments to be described by the model were conducted in a continuous flow apparatus with premixed and pre-heated synthesis gas of composition $\mathrm{H}_{2} / \mathrm{CO} / \mathrm{CO}_{2} / \mathrm{N}_{2}(65 / 25 / 5 / 5 \mathrm{~mol} \%)$. The IMPBRE geometry to be simplified by the model consists of eight parallel reaction slits with hexagonally arranged pillar structures inside. The pillars are $0.8 \mathrm{~mm}$ in diameter and the distance between centres of adjacent pillars is $1.6 \mathrm{~mm}$. Each reaction slit has the dimensions of $(\mathrm{W} \times \mathrm{H} \times \mathrm{L}$ : $8.0 \times 0.8 \times 60 \mathrm{~mm}^{3}$ ) and is sandwiched between two neighbouring cooling oil slits. For heat exchange, $0.25 \times 0.5 \mathrm{~mm}^{2}$ cross flow oil slits with $0.25 \mathrm{~mm}$ wide fins between slits are made in $0.5 \mathrm{~mm}$ thick metal foils. A high temperature oil thermostat (Julabo HT30) was used to maintain the temperature in the range of 293 to $575 \mathrm{~K}$. A flowsheet of the experimental setup is shown in Fig. 1 and details of the IMPBRHE and arrangement of reaction slits and oil slits are shown in Fig. 2 Further details of reactor fabrication, catalyst loading and testing procedures, as well as temperature measurement have been described elsewhere [11]. Contact time is defined for experiment and model as the ratio of catalyst mass to volumetric flow rate of syngas at STP.

The model for reaction mass balance and heat transfer was implemented in COMSOL Multiphysics software. This is a finite element based package which couples convection-diffusion and convectionconduction modules for mass and energy balances respectively.

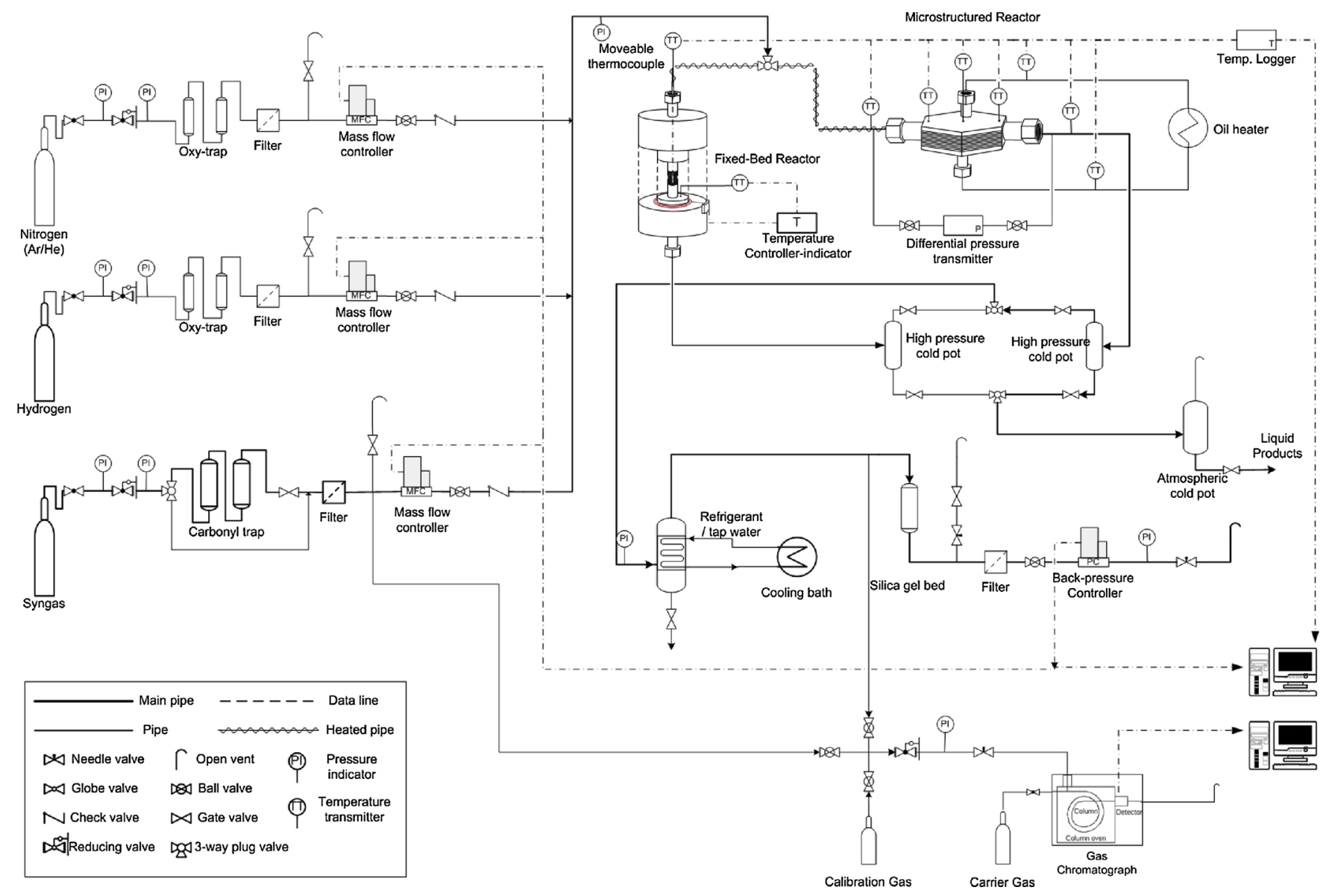

Fig. 1. Experimental setup. Methanol synthesis in microstructured reactor-heat-exchanger. 
(a)

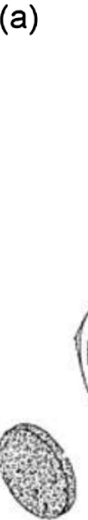

Frit

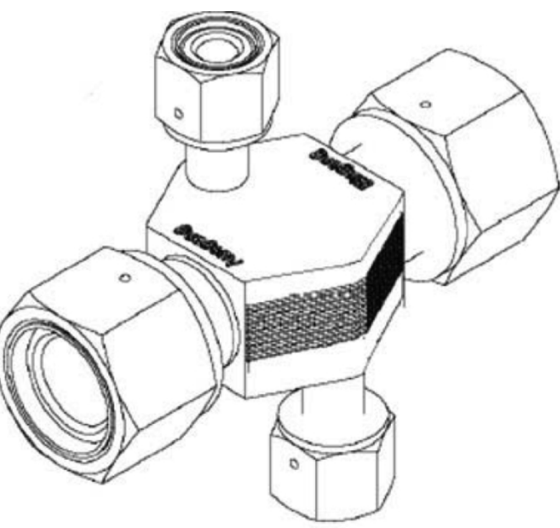

Reactor (b)

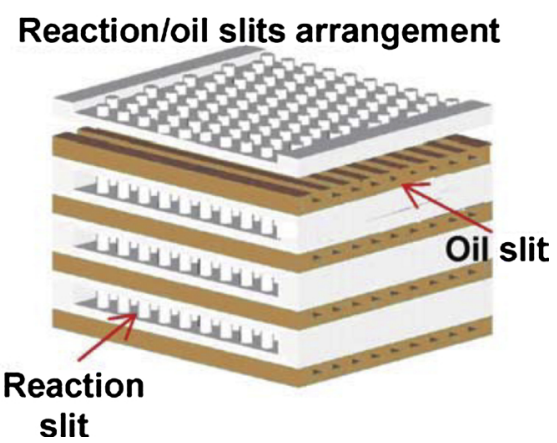

Fig. 2. (a) Integrated micro packed bed reactor - heat exchanger for methanol synthesis. (b) Arrangement of reaction slits and oil slits. Data from [12].

Since application of Mears' criteria and the use of 80-micron particles already indicated the lack of external and internal mass transfer as well as internal heat transport limitations, a three-dimensional pseudohomogeneous model for a real 3D pillar geometry filled with particles may be considered representative of the external/intra-particle heat transfer and the temperature dependent reactions inside the microchannel reactor. The model was developed based on a simplified slit geometry without pillars. The volume difference between the simplified and real slit was adjusted by the bed density and in return, the effect of higher surface area provided by the pillars was taken into account through a correction factor for the heat resistance at particle-wall interface.

Temperature and concentration changes along the slit height $(\mathrm{z})$ are assumed to be negligible, but dispersion and heat transfer effects along slit length (x) and width (y) are included in the model. Constant velocity, viscosity and density along slit dimensions were considered for simplicity. Constant velocity means that flow bypass (i.e channeling) near the walls is considered negligible. Extensive discussions on this issue can be found in previous publications $[11,21]$.

\subsection{Kinetic module}

A kinetic rate expression for methanol synthesis should include reaction rates for both methanol formation and water gas shift and be able to describe the variation in gas composition and temperature over integral reactors. An overview over proposed kinetic models is given by van den Bussche and Froment [22] and Skrzypek et al. [23]. In this work, the steady-state kinetic rate expressions obtained by van den Bussche and Froment based on a Langmuir-Hinshelwood model for methanol synthesis via $\mathrm{CO}_{2}$ hydrogenation and the reverse water gas shift reactions over commercial $\mathrm{Cu} / \mathrm{ZnO} / \mathrm{Al}_{2} \mathrm{O}_{3}$ catalyst have been applied:

$$
\begin{array}{r}
r_{\mathrm{MeOH}}=\frac{k_{d} \cdot p_{\mathrm{CO}_{2}} \cdot p_{\mathrm{H}_{2}} \cdot\left(1-\frac{p_{\mathrm{H}_{2} \mathrm{O}} \cdot p_{\mathrm{CH}_{3} \mathrm{OH}}}{p_{\mathrm{H}_{2}} \cdot p_{\mathrm{CO}_{2}} \cdot K_{e q 1}}\right)}{\left(1+k_{c} \cdot \frac{p_{\mathrm{H}_{2} \mathrm{O}}}{p_{\mathrm{H}_{2}}}+\sqrt{p_{\mathrm{H}_{2}} \cdot k_{a}}+k_{b} \cdot p_{\mathrm{H}_{2} \mathrm{O}}\right)^{3}} \\
r_{\mathrm{RWGS}}=\frac{k_{e} \cdot p_{\mathrm{CO}_{2}} \cdot\left(1-K_{e q 2} \cdot p_{\mathrm{H}_{2} \mathrm{O}} \cdot \frac{p_{\mathrm{CO}}}{P_{\mathrm{CO}_{2} \cdot p_{H_{2}}}}\right)}{\left(1+k_{c} \cdot \frac{p_{\mathrm{H}_{2} \mathrm{O}}}{p_{\mathrm{H}_{2}}}+\sqrt{p_{\mathrm{H}_{2}} \cdot k_{a}}+k_{b} \cdot p_{\mathrm{H}_{2} \mathrm{O}}\right)}
\end{array}
$$

Kinetic and equilibrium constants of the above expressions are obtained from [22] and the values are given in Table 1. The Chemical Reaction Engineering Lab (CREL) module of COMSOL Multiphysics was used to introduce the kinetic model. Thermodynamic properties for equilibrium constants were calculated by the Chemkin ${ }^{\circledR}$ simulation software.

\subsection{Governing equations}

The mass balance equation implemented in the convection and diffusion application mode is given by:

$D_{e x}\left[\frac{\partial^{2} C_{i}}{\partial x^{2}}\right]+D_{e z}\left[\frac{\partial^{2} C_{i}}{\partial z^{2}}\right]=u_{s} \frac{\partial C_{i}}{\partial x}-\rho_{B} \cdot r_{i}$

Here, $\mathrm{C}_{\mathrm{i}}$ and $\mathrm{r}_{\mathrm{i}}$ are the concentration and reaction rate of specie $i$, respectively. $u_{s}$ is the superficial linear velocity and $\mathrm{D}_{\mathrm{ex}}$ and $\mathrm{D}_{\mathrm{ez}}$ are the effective diffusivities. Similarly, the convection and conduction application mode for the energy balance equation is:

$\lambda_{e x} \frac{\partial^{2} T}{\partial x^{2}}+\lambda_{e z} \frac{\partial^{2} T}{\partial z^{2}}=u_{s} \cdot \rho_{f} \cdot c_{p} \frac{\partial T}{\partial x}-\rho_{B} \cdot(\Delta H) \cdot r_{i}$

$\lambda_{\text {ex }}$ and $\lambda_{\text {ez }}$ are effective gas thermal conductivities along the slit length and width, $c_{p}$ is the specific heat capacity and $\rho_{\mathrm{f}}$ and $\rho_{\mathrm{B}}$ are gas phase and catalyst bed densities, respectively.

Initial concentrations are set equal to the feed gas composition at the slit inlet. At the reactor slit inlet and outlet the mass flux is assumed equal to convective mass flux (no mass flux due to diffusion) and zero at the channel walls. Similarly, the initial temperature is set equal to the feed gas temperature. The heat flow rate at the reactor exit is set equal to the convective heat flux. Slit wall temperatures are set equal to the inlet temperature of heat transfer oil. This has been addressed experimentally and will be further discussed in the results and discussion section.

Table 1

Kinetic parameters for $\mathrm{MeOH}$ synthesis from syngas (Eq 4 \& 5). Data from Van den Bussche and Froment [22]. Parameter = A exp (B/RT). Pressure in bar, reaction rate in $\mathrm{mol} / \mathrm{kg}_{\text {cat }} \mathrm{S}$.

\begin{tabular}{llll}
\hline & $\mathrm{A}$ & $\mathrm{B}$ & Parameter in [22] \\
\hline$k_{c}$ & 3453.88 & - & $K_{H_{2} O} / K_{8} K_{9} K_{H_{2}}$ \\
$k_{b}$ & $6.62 \times 10^{-11}$ & 124.119 & $K_{H_{2} O}$ \\
$\sqrt{k_{a}}$ & 0.499 & 17.197 & $\sqrt{k_{H 2 O}}$ \\
$k_{d}$ & 1.07 & 36.696 & $K_{5 a} K_{2}^{\prime} K_{3} K_{4} K_{H_{2}}$ \\
$k_{e}$ & $1.22 \times 10^{10}$ & -94.765 & $K_{1}^{\prime}$ \\
$K_{\text {eq. } 1}$ & $\log _{10} k_{1}^{*}=\frac{3066}{\mathrm{~T}}-10.592$ & & $k_{1}^{*}$ \\
$K_{\text {eq. } 2}$ & $\log _{10} 1 / K_{3}^{*}=-\frac{2073}{T}+2.029$ & $K_{3}^{*}$ \\
& & & \\
\hline
\end{tabular}


The boundary conditions with regard to: The flow direction coordinate $\mathrm{x}\left(0\right.$ to $\left.\mathrm{L}_{\text {slit }}\right)$, the slit height coordinate $\mathrm{z}\left(0\right.$ to $\left.\mathrm{H}_{\text {slit }}\right)$ and the slit with coordinate y (0 to $\mathrm{W}_{\text {slit }}$ ) can be summarized as follows [12] :

$\mathrm{C}_{\mathrm{i}}=\mathrm{C}_{\mathrm{i}, \mathrm{f}}, \mathrm{T}=\mathrm{T}_{\mathrm{f}}$ at $\mathrm{x}=0$

$\frac{\partial C_{i}}{\partial x}=0, \frac{\partial T}{\partial x}=0$ at $\mathrm{x}=\mathrm{L}_{\text {slit }}$

$\frac{\partial C_{i}}{\partial x}=0,-\lambda_{e r} \frac{\partial T}{\partial z}=a_{w}\left(T-T_{w}\right)$ at $z=0$ and $H_{\text {slit }}$

$\frac{\partial C_{i}}{\partial y}=0, \frac{\partial T}{\partial y}=0$, at $\mathrm{y}=0$ and $\mathrm{y}=\mathrm{W}_{\text {slit }}$

The boundary conditions for $\mathrm{y}$ and $\mathrm{x}$ directions are different since the slit wall and cooling oil channel are only adjacent in the $\mathrm{xz}$ plane at $\mathrm{y}=0$ and $\mathrm{H}_{\text {slit }}$.

\subsection{Model parameters}

The effective mass diffusivities and heat conductivities are essential parameters for the model equations, and are estimated based on gas superficial velocity. A slit hydraulic diameter was used as characteristic dimension. Since low Reynolds numbers are applied, a careful selection and adoption of suitable correlations for model parameters seems critical and hence necessary. The effective diffusivity along the slit length are estimated by Wen and Fun [24] and along the slit width by de Ligny [25]. The effective gas phase thermal conductivities in both directions are calculated by correlations suggested by Yagi and Kunii [26]. The overall slit heat transfer coefficient was estimated by Froment and Bischoff [27].

\section{Results and discussion}

The experimental performance of the IMPBRHE has been extensively discussed in our previous publications as reviewed in the Introduction. The main attention here will be on the simulation results, while comparison and reference to the experimental results will be made for further validation.

\subsection{Simulation of methanol synthesis kinetics}

Figs. $3 \mathrm{a}$ and $3 \mathrm{~b}$ show $1 \mathrm{D}$ simulation results obtained by the methanol synthesis kinetic module at an inlet temperature of $528 \mathrm{~K}$ and 80 bar under adiabatic conditions. The change in concentrations can be explained by a reaction path in series i.e. conversion of $\mathrm{CO}$ to $\mathrm{CO}_{2}$ and water through water gas shift reaction followed by hydrogenation of $\mathrm{CO}_{2}$ to methanol. Since the reactions are exothermic and equilibrium limited, the reaction rate in the beginning of the bed is mainly controlled by the temperature. As conversion increases along the reactor length, the reaction rate is restrained by the approach to equilibrium. This is why the concentrations of methanol and water only increase initially. (Fig. 3a), and why temperature profile approaches a constant value (Fig. 3b). A total adiabatic temperature increase of about $90 \mathrm{~K}$ is obtained in the plug flow reactor. The adiabatic temperature rise in methanol synthesis depends on the initial temperature $\left(\mathrm{T}_{0}\right)$ and concentration $\left(\mathrm{C}_{\mathrm{A} 0}\right)$, heat of reaction as well as gas phase density $\left(\rho_{g}\right)$ and specific heat $\left(\mathrm{C}_{\mathrm{p}}\right)$ :

$\frac{\Delta T_{a d}}{T_{0}}=\frac{(-\Delta H) C_{A 0}}{\rho_{g} C_{p} T_{0}}$

\subsection{Thermal stability of the IMPBRHE}

Thermal stability is a key factor to the performance of any reactor handling exothermic reactions. Fig. 4a shows simulation results of temperature distribution in the IMPBRHE at a contact time of $120 \mathrm{msec}$
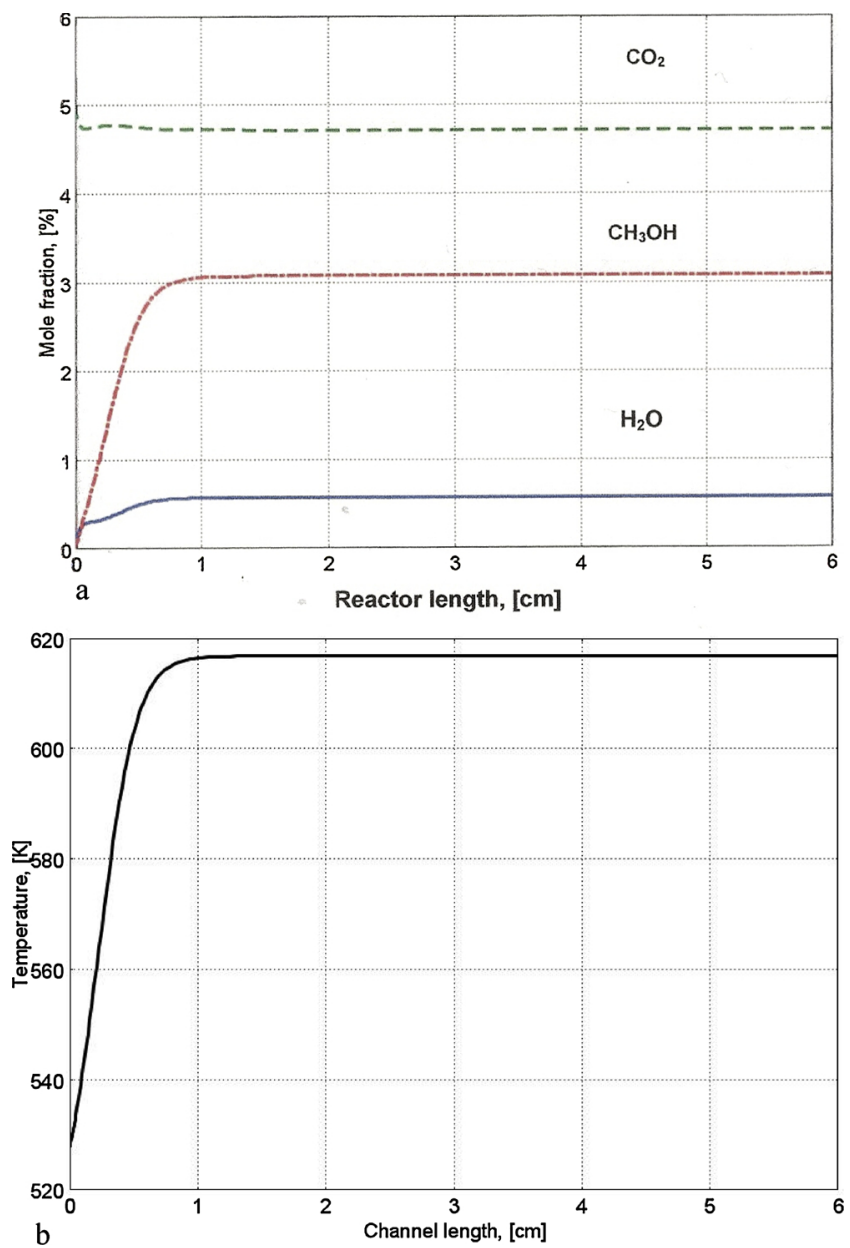

Fig. 3. Simulation results obtained from methanol synthesis kinetic module in an adiabatic reactor, (a) concentration profiles (mole fraction) of methanol, water and $\mathrm{CO}_{2}$ along the reactor, (b) temperature profile. Operating conditions: $528 \mathrm{~K}$ and 80 bar, synthesis gas composition $\mathrm{H}_{2} / \mathrm{CO} / \mathrm{CO}_{2} / \mathrm{N}_{2}: 65 / 25 / 5 / 5 \mathrm{~mol} \%$, catalyst bed density: $1050 \mathrm{~kg} / \mathrm{m}^{3}$.

$\mathrm{g} / \mathrm{ml}$ and feed gas temperature of $493 \mathrm{~K}$. Except a sharp temperature rise within a short region near the entrance $(2-3 \mathrm{~mm})$ due to lower reaction gas inlet temperature, the slit remains isothermal; equal to the wall/oil temperature of $528 \mathrm{~K}$. This is in agreement with experimental temperature measurements in the slits demonstrating that the slit operates isothermally regardless of productivity level (contact time) and also operating temperature. To further demonstrate the heat transfer capability of the IMPBRHE relative to tubular packed reactors, the temperature distribution over a laboratory scale fixed-bed reactor (3.0 cm length and $0.914 \mathrm{~cm}$ diameter) at the same operating conditions but with a maximum hot-spot temperature of $528 \mathrm{~K}$ is shown in Fig. $4 \mathrm{~b}$. The maximum temperature zone appears in the centre line of the reactor. Due to limited heat transfer to the wall, the temperature at the wall is colder than other parts. The large temperature gradient over the tube radius indicates that catalyst particles close to the reactor wall are not being used efficiently.

Since the applied model is pseudo-homogeneous for the microstructured reactor as well as the laboratory fixed bed reactor, we also must discuss possible temperature gradients inside the catalyst particles before drawing a conclusion as to whether temperature gradients in the IMPBRHE can be neglected. According to literature, the temperature rise is maximum $0.1 \mathrm{~K}$ over a commercial $\mathrm{Cu} / \mathrm{ZnO} / \mathrm{Al}_{2} \mathrm{O}_{3}$ catalyst of 150 to $200 \mu \mathrm{m}$ particle size [28]. Since $50-80 \mu \mathrm{m}$ particles were used in the present work, the temperature gradients in the micro fixed bed are at least higher than in the particles which verifies our assumptions. 


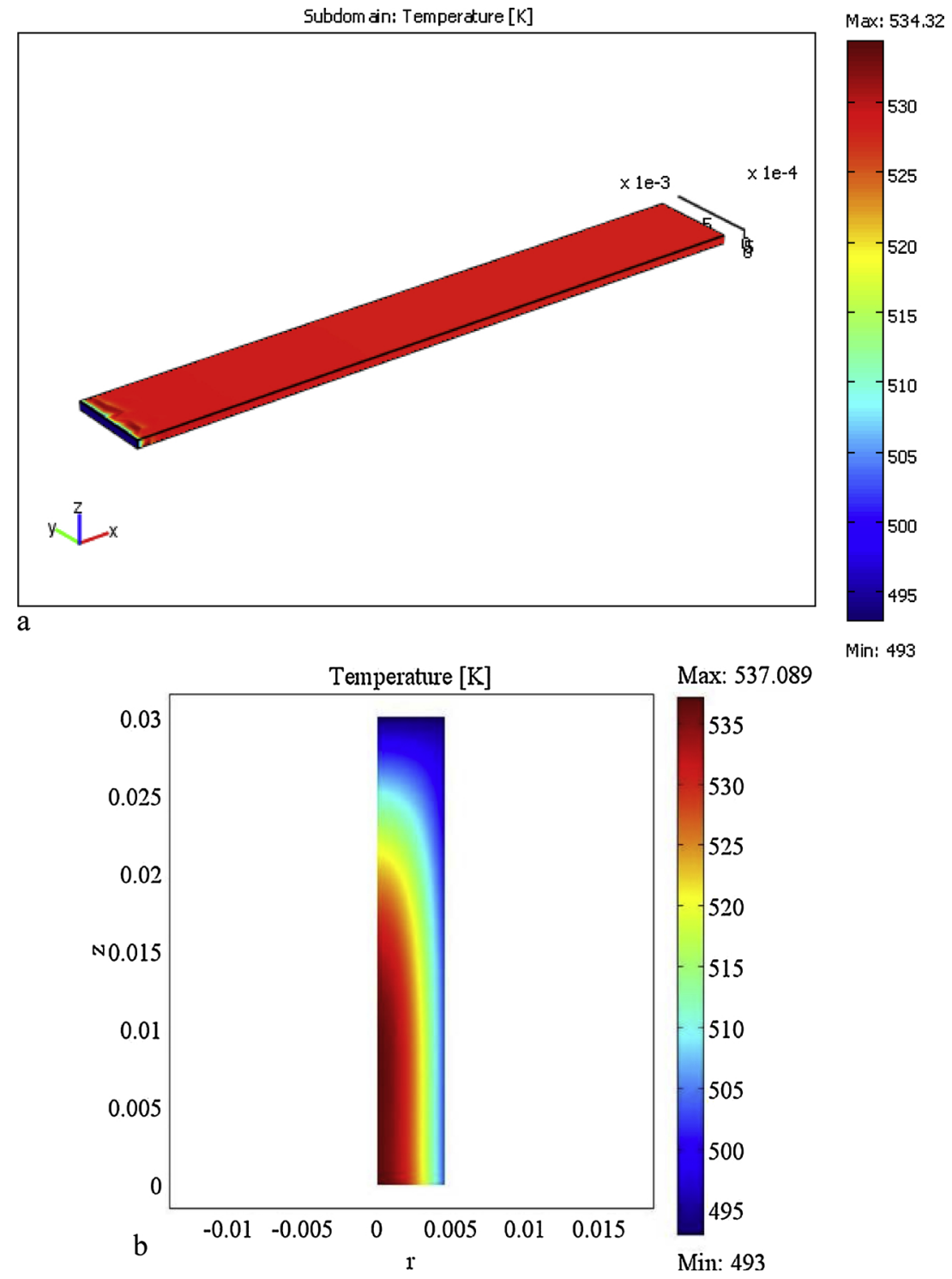

Fig. 4. Simulation of temperature profile (a) over the single reaction slit at wall temperature of $528 \mathrm{~K}$, (b) in a tubular fixed-bed reactor with id $=9.14 \mathrm{~mm}$ at maximum bed temperature of $528 \mathrm{~K}$. Results were obtained at identical conditions including pressure of 80 bar, synthesis gas composition $\mathrm{H}_{2} / \mathrm{CO} / \mathrm{CO} / \mathrm{N}_{2}: 65 / 25 / 5 /$ $5 \mathrm{~mol} \%$ and $\mathrm{W} / \mathrm{F}$.

Copper based catalysts are highly selective towards methanol, but local hot spots may cause sintering and agglomeration of $\mathrm{Cu}$ and hence deactivation of the catalyst [29]. The isothermal performance of the IMPBRHE, investigated numerically and experimentally in this work, may lead to better control of the reaction, suggests potential improvement in catalyst lifetime, as well as lower propensity towards by-product formation.

In Fig. 5, the temperature profile in the reaction slit centre line upon variation of the contact time at a wall temperature of $528 \mathrm{~K}$ and $80 \mathrm{bar}$ is shown. At high contact time, a decrease in temperature towards the reaction slit outlet occurs, and the maximum temperature gradient $(\sim 0.9 \mathrm{~K})$ along the reaction slit is obtained for the longest contact time (308 $\mathrm{ms} \cdot \mathrm{g} / \mathrm{ml})$. Practially no temperature gradient is associated with very low contact time $(50 \mathrm{~ms} \cdot \mathrm{g} / \mathrm{ml})$. This can be explained by higher methanol formation rate (up to 6-fold) at low contact time. In other words, the kinetic regime is dominant at the reactor outlet and equilibrium is not limiting. However, the results indicate a stable thermal behaviour in a wide range of space velocities.
Fig. 6 presents the effect of feed gas temperature on the temperature profile along the slit centre line at a wall temperature of $528 \mathrm{~K}$ and $80 \mathrm{bar}$. In case of relatively cold feed gas temperature ( $483 \mathrm{~K}$ ), a rapid rise in temperature along the first $\sim 2 \mathrm{~mm}$ of the slit occurs followed by flat profile at a temperature very close to the wall temperature. Negligible effect of feed gas temperature on the productivity of the IMPBRHE was also demonstrated experimentally [11]. Hence, the system is relatively insensitive to variation in the feed gas temperature.

A challenging task in experimental performance evaluation of microchannel reactors is measurement of the actual temperature inside the slit, due to small dimensions and limited access. In case of methanol synthesis, this is even more difficult with respect to simultaneously controlling leaks at high operating pressure. Our measurements showed, however, that the controlling factor for the slit temperatures is the inlet oil temperature (Fig. 7). A reproducible correlation between the measured slit temperature, skin temperatures (both measured near the middle point along the slit length) and the inlet oil temperature was established provided that the system is well insulated [11]. 


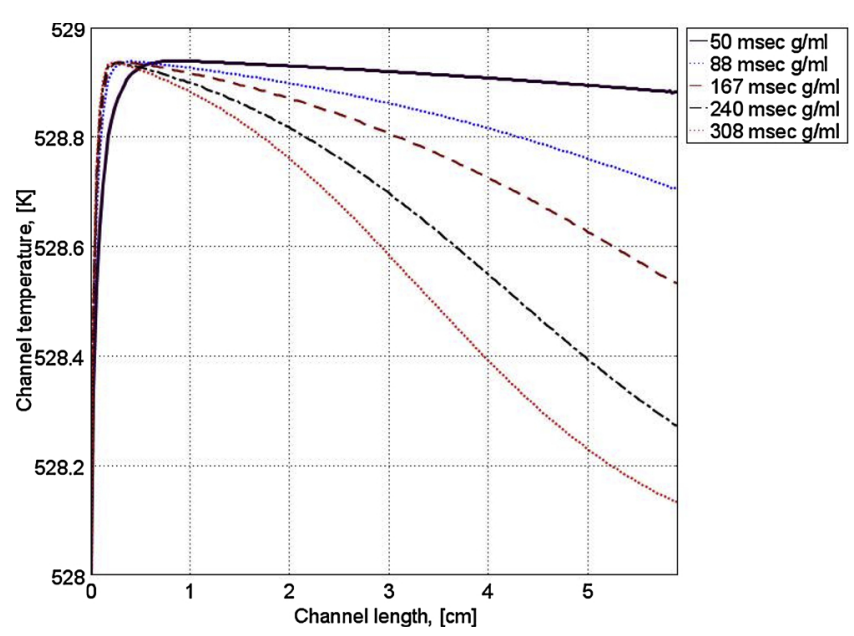

Fig. 5. Simulation results showing the effect of variation of contact time on the temperature profile along the single reaction slit at wall temperature of $528 \mathrm{~K}$ and 80 bar, synthesis gas composition $\mathrm{H}_{2} / \mathrm{CO} / \mathrm{CO}_{2} / \mathrm{N}_{2}: 65 / 25 / 5 / 5 \mathrm{~mol} \%$.

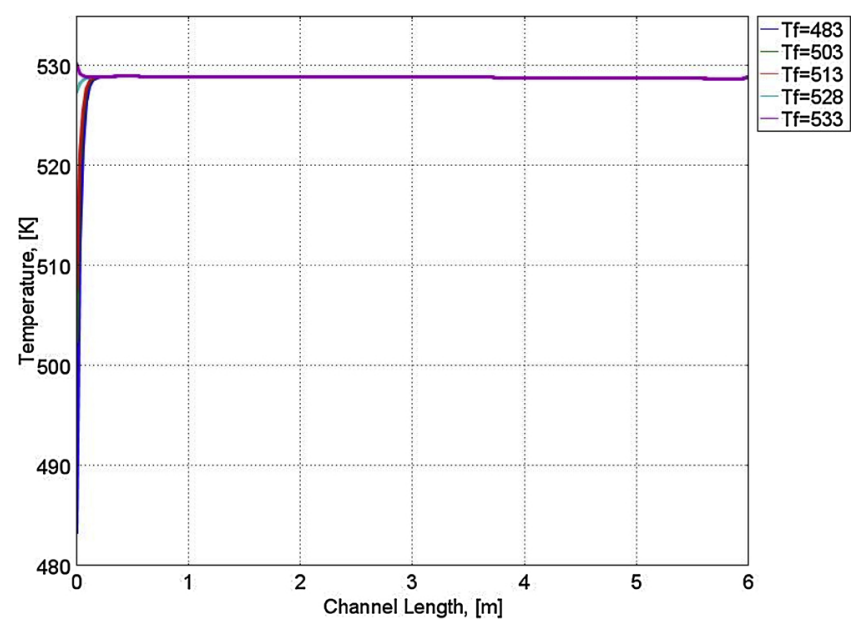

Fig. 6. Effect of variation of the feed gas temperature on temperature profile along the reaction slit at wall temperature of $528 \mathrm{~K}$ and $80 \mathrm{bar}$, contact time $120 \mathrm{msec} \mathrm{g} / \mathrm{ml}$ and synthesis gas composition $\mathrm{H}_{2} / \mathrm{CO} / \mathrm{CO}_{2} / \mathrm{N}_{2}: 65 / 25 / 5 / 5 \mathrm{~mol} \%$.

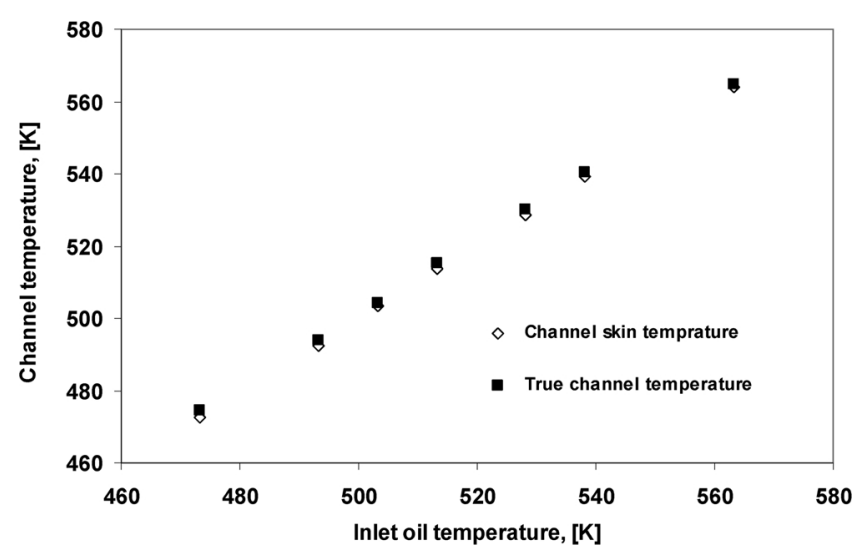

Fig. 7. Slit temperature measurements against inlet oil temperatures in IMPBRHE at methanol synthesis operating conditions. Both slit temperatures and reactor skin temperatures (measured at outer surface of the slits) were measured at the middle of the slit length. Synthesis gas composition $\mathrm{H}_{2} / \mathrm{CO}$ / $\mathrm{CO}_{2} / \mathrm{N}_{2}: 65 / 25 / 5 / 5 \mathrm{~mol} \%$.
The developed model was applied further to validate reaction slit measurements at different operating temperatures and fixed contact time of $120 \mathrm{msec} \mathrm{gr} / \mathrm{ml}$ and 80 bars. Fig. 8 presents the temperature profiles along the centre line of the reaction slit for different wall temperatures (equivalent to inlet oil temperatures). The results show agreement between simulation and experiments on isothermal operation in the reaction slits.

\subsection{Performance evaluation of IMPBRHE}

The effect on the CO conversion upon variation of the contact time is shown in Fig. 9. As to be expected, the conversion of $\mathrm{CO}$ decreases as the syngas flow rate increases due to less contact time between catalyst particles and the gas phase. Contact times of higher than $300 \mathrm{~ms} \mathrm{~g} / \mathrm{ml}$ are required to reach close to equilibrium CO conversion (63\%) for the catalyst and conditions applied. The results also present a good agreement between the simulation and experimental data at identical operating conditions. Similar commercial $\mathrm{Cu} / \mathrm{ZnO} / \mathrm{Al}_{2} \mathrm{O}_{3}$ systems were used both in the experiments in this work and in the development of the kinetic expression applied in the model [22]. The activity level of the catalyst we used in the experiments is lower than the catalyst that was used to develop the kinetic expression by van den Bussche and Froment. Both the catalysts used in the experiments and in the kinetic expression applied in the model [22] are commercial $\mathrm{Cu} / \mathrm{ZnO} / \mathrm{Al}_{2} \mathrm{O}_{3}$ systems with similar properties but different activity levels. A correlation between activity of catalyst and operating temperature was used in the model and resulted in proper fit to the laboratory generated data. Due to very low Reynolds numbers (around 1) in our experimental studies and thus dominance of molecular diffusion, verification of external mass transfer limitations in IMPBRHE could be done by manipulation of diffusion coefficients while keeping the reaction kinetics unchanged. Variation of total pressure and change of inert gas are proper methods to implement this strategy. Extensive discussion on proper method for investigation of mass transfer limitation in microstructured reactors could be found elsewhere $[20,30,31]$. Since we already assumed a pseudo-homogenous model for the reaction slit we can not discuss the effects of external mass transfer to the catalyst by help of this simulation. However, if local temperatures are different in the reactor the overlay of different local reaction rates could produce an inhomogeneous concentration field. To check this issue of the overlaid temperature field Fig. 10 shows the local concentration distribution of $\mathrm{CO}\left(\mathrm{mol} / \mathrm{m}^{3}\right)$ over the slit cross section of

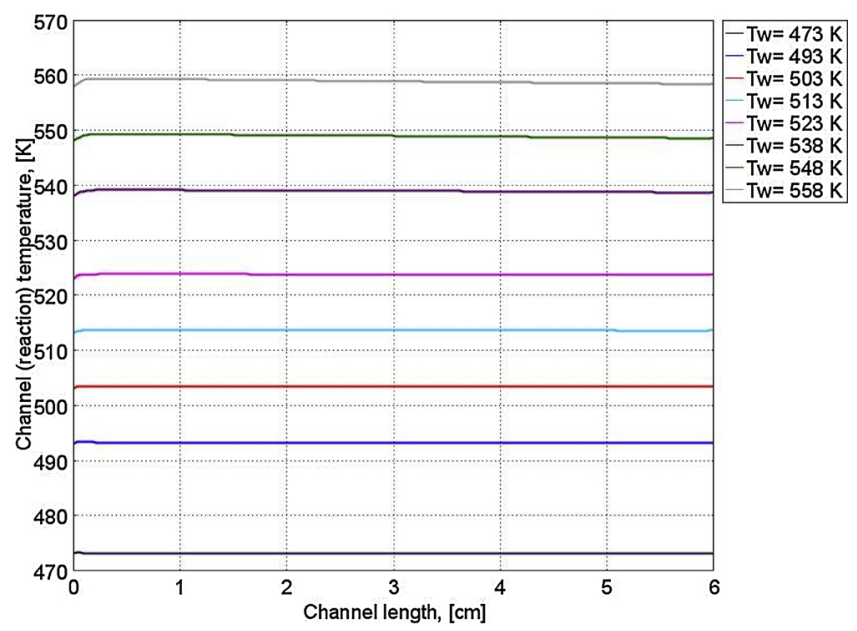

Fig. 8. Simulated temperature profiles along the reaction slit length upon variation of wall temperature. Pressure of $80 \mathrm{bar}$, contact time $120 \mathrm{msec} \mathrm{g} / \mathrm{ml}$ and synthesis gas composition $\mathrm{H}_{2} / \mathrm{CO} / \mathrm{CO}_{2} / \mathrm{N}_{2}: 65 / 25 / 5 / 5 \mathrm{~mol} \%$. 


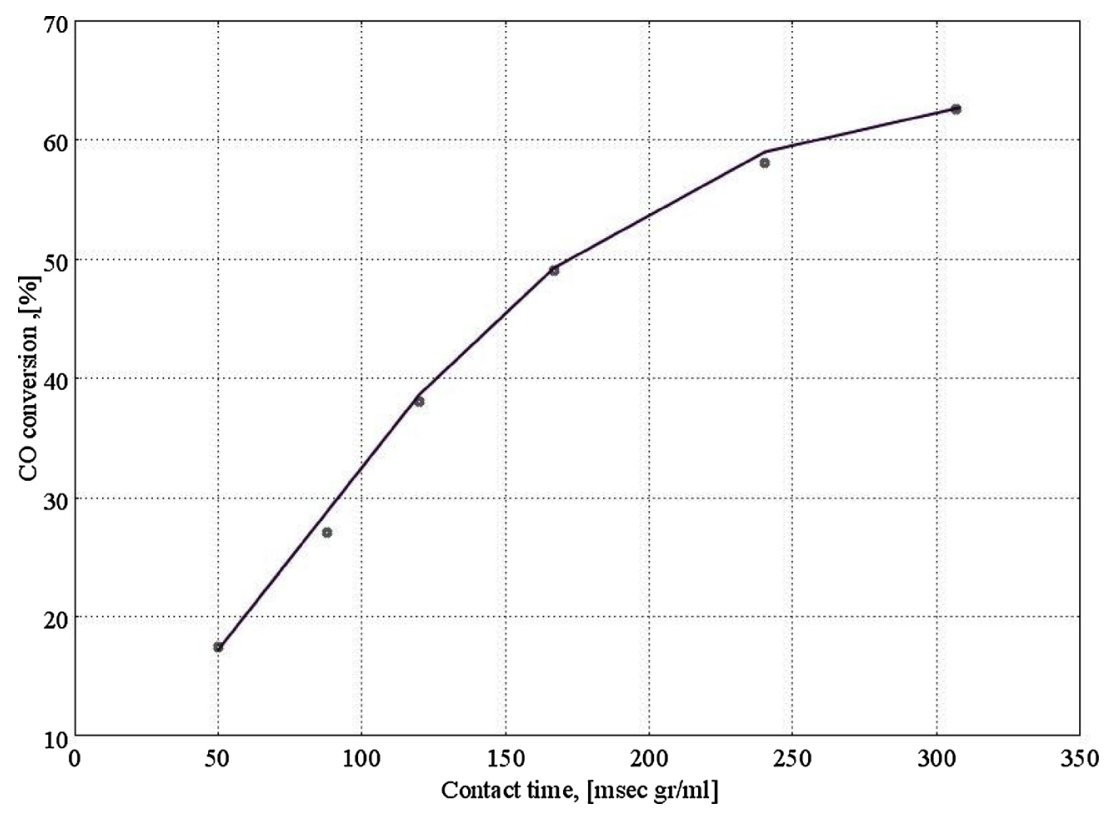

Fig. 9. CO conversion against variation of the contact time in the IMPBRHE predicted by the model (solid line) and experimental data (points). Wall temperature $528 \mathrm{~K}$ and 80 bar, synthesis gas composition $\mathrm{H}_{2} / \mathrm{CO} / \mathrm{CO}_{2} / \mathrm{N}_{2}: 65 / 25 / 5 / 5 \mathrm{~mol} \%$.

IMPBRHE at 80 bar and $528 \mathrm{~K}$ and at the slit length of $2 \mathrm{~cm}$. As it could be seen, the concentration over the cross section is reasonably uniform and no significant gradients exist.

In the laminar regime and with small particle size, the mass transfer mechanism along the cross section is diffusion. To further see the effect of diffusion rate, $\mathrm{CO}$ conversion at the reactor exit obtained by model upon variation of effective diffusion coefficients is shown in Fig. 11. A wide range of diffusion coefficients (up to $300 \%$ increase) results in no significant change in the reactor performance. This means that slight temperature fields inside the reaction slit are not influencing the reactor performance by arising concentration fields.

\section{Conclusion}

A mathematical pseudo-homogenous reactor model was developed to evaluate performance of methanol synthesis in a single slit packed bed microstructured-heat exchanger for synthesis of methanol from synthesis gas $\mathrm{Cu} / \mathrm{ZnO} / \mathrm{Al}_{2} \mathrm{O}_{3}$ commercial catalyst. The model demonstrates from a fundamental perspective that the microstructured reactors are capable of providing superior heat and mass transport configurations. Both simulation and experiments validated the concept of isothermal operation of the reaction slit for such a highly exothermic reaction under a variety of industrially relevant methanol synthesis

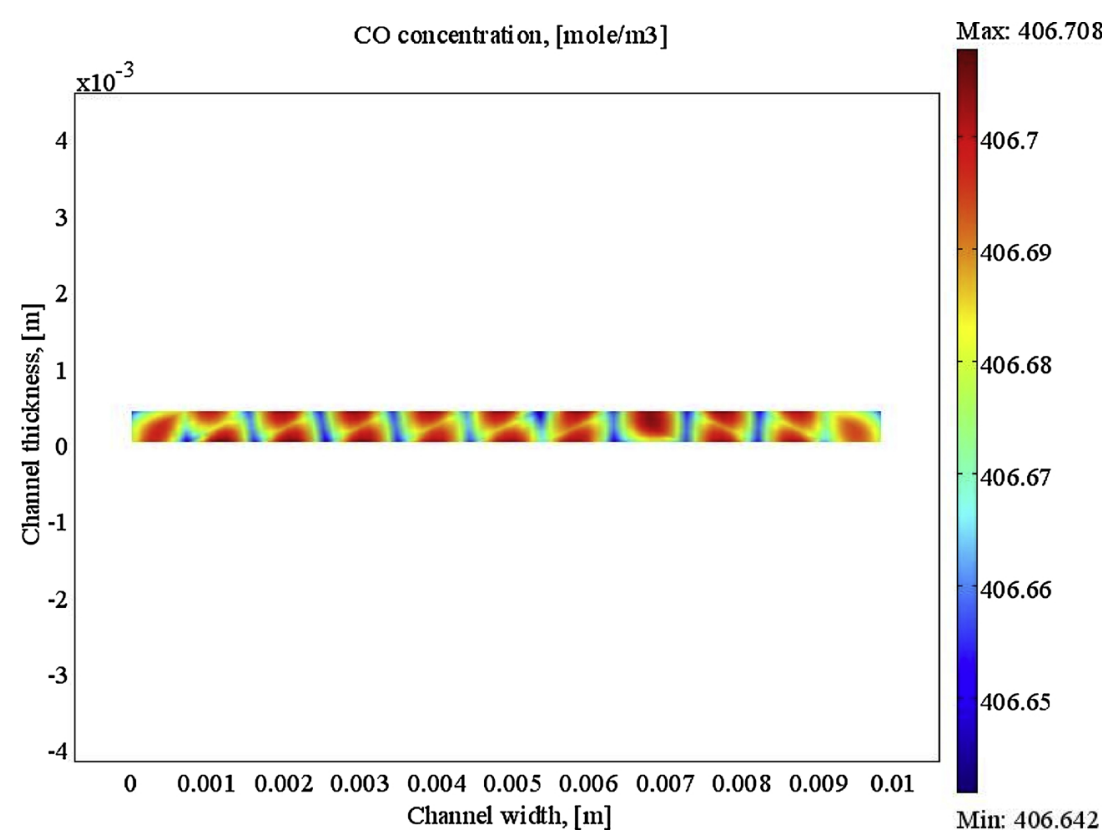

Fig. 10. Concentration of $\mathrm{CO}\left(\mathrm{mol} / \mathrm{m}^{3}\right)$ over channel cross section of IMPBRHE at $80 \mathrm{bar}$ and $528 \mathrm{~K}$ and at a channel length of $2 \mathrm{~cm}$. Wall temperature $528 \mathrm{~K}$ and 80 bar, contact time $120 \mathrm{msec} g r / m l$, synthesis gas composition $\mathrm{H}_{2} / \mathrm{CO} / \mathrm{CO}_{2} / \mathrm{N}_{2}: 65 / 25 / 5 / 5 \mathrm{~mol} \%$. 


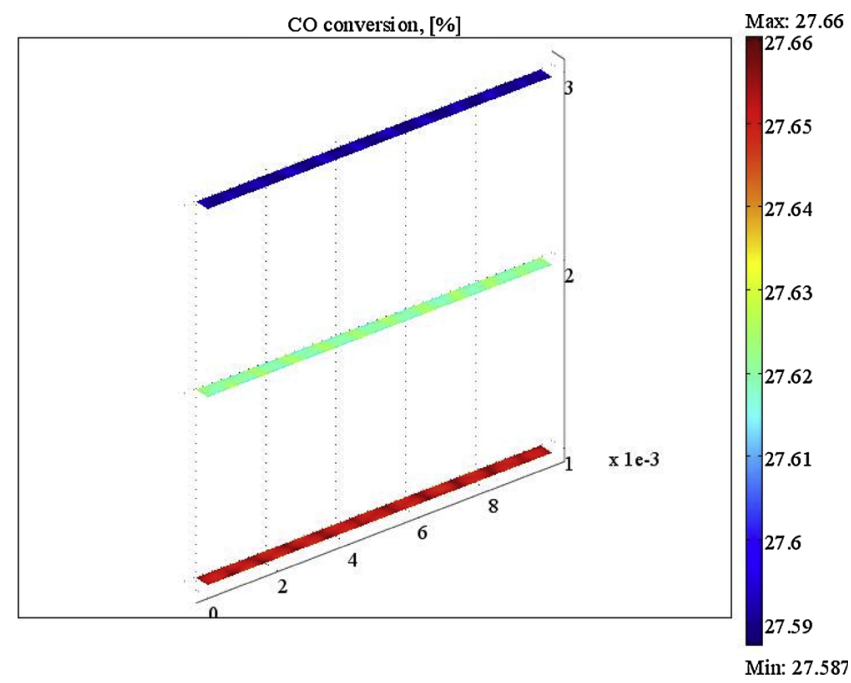

Fig. 11. Simulation of CO conversion at the IMPBRHE exit cross section $\left(0.8 \times 8 \mathrm{~mm}^{2}\right.$ shown along $\mathrm{x}$-axis) upon variation of effective diffusion coefficients shown in y-axis at three different values of 1.0, 2.0 and $3.0 \times 10^{-3} \mathrm{~m}^{2} / \mathrm{s}$. CO conversion levels are given using colour code bar at the right side of the figure. Wall temperature $528 \mathrm{~K}$ and $80 \mathrm{bar}$, contact time $120 \mathrm{msec} \mathrm{gr} / \mathrm{ml}$, synthesis gas composition $\mathrm{H}_{2} / \mathrm{CO} / \mathrm{CO}_{2} / \mathrm{N}_{2}: 65 / 25 / 5 / 5 \mathrm{~mol} \%$.

operating conditions. Simulation results also reveal that the microstructured reactor is working free of performance loss due to concentrations field which might come up from overlaid temperature fields. The developed model predicts the productivity of the IMPBRHE with an acceptable deviation and could be used as a tool for optimization of operating conditions, reactor productivity and the design of a larger reactor. The results obtained, may highlight the promising benefits of micro process technology for process intensification purposes and more specifically for highly exothermic compact gas to liquid (GTL) technology.

\section{Acknowledgement}

This publication forms a part of the "Remote Gas" project, performed under the strategic Norwegian Research program PETROMAKS. The authors acknowledge the partners; Statoil, UOP, Bayerngas Norge, Aker Solutions, DNV and the Research Council of Norway (168223/ S30) for support.

\section{References}

[1] A.R.C. Hassel, J.C. Schouten, J. Yoshida, Handbook of Micro Process Engineering, Wiley-Verlag, 2009.

[2] H.J. Venvik, J. Yang, Catalysis in Microstructured Reactors. Short review on smallscale syngas production and further conversion into methanol, DME and FischerTropsch products, Catalysis Today 285 (2017) 135-146.

[3] P. Pfeifer, Catalytic partial oxidation and oxidative steam reforming, in: A.R.C. Hessel, J.C. Schouten, J. Yoshida (Eds.), Handbook of Micro Process Engineering, Wiley Verlag, 2009, pp. 445-464.

[4] R. Guettel, T. Turek, Assessment of micro-structured fixed-bed reactors for highly exothermic gas-phase reactions, Chemical Engineering Science 65 (5) (2010) 1644-1654.

[5] P. Pfeifer, et al., Investigations on a $\mathrm{Pt} / \mathrm{TiO}_{2}$ catalyst coating for oxidation of $\mathrm{SO}_{2}$ in a microstructured reactor for operation with forced decreasing temperature profile, Applied Catalysis A: General 391 (1) (2011) 289-296.

[6] P. Pfeifer, et al., One pass synthesis of pure sulphur trioxide in microreactors, Chimica Oggi 25 (2) (2007) 42-46.

[7] A.M. Hilmen, et al., Fischer-Tropsch synthesis on monolithic catalysts with oil circulation, Catalysis Today 105 (3) (2005) 357-361.

[8] Y. Wang, et al. Fischer-Tropsch synthesis using microchannel technology and novel catalysts and microchannel reactor. US Patent WO2005075606B1, 2005-11-17.

[9] R. Myrstad, et al., Fischer-Tropsch synthesis in a microstructured reactor, Catalysis Today 147 (2009) S301-S304.

[10] A. Holmen, et al., Monolithic, microchannel and carbon nanofibers/carbon felt reactors for syngas conversion by Fischer-Tropsch synthesis, Catalysis Today 216 (2013) 150-157.

[11] H. Bakhtiary-Davijany, et al., Characteristics of an Integrated Micro Packed Bed Reactor Heat Exchanger for methanol synthesis from syngas, Chemical Engineering Journal 167 (2) (2011) 496-503.

[12] F. Hayer, et al., Synthesis of dimethyl ether from syngas in a microchannel reactor-Simulation and experimental study, Chemical Engineering Journal 167 (2) (2011) 610-615

[13] S. Lee, Methanol synthesis technology, CRC Press. Inc., Boca Raton, Florida, 1990.

[14] J.B. Hansen, P.E. Højlund Nielsen, Chap.13.13 Methanol Synthesis, in: G. Ertl, H. Knoezinger, F. Schuth, J. Weitkamp (Eds.), Handbook of Heterogeneous Catalysis, Wiley-VCH Verlag GmbH\&Co. KGaA, Weinheim, 2008.

[15] F. Studt, et al., The Mechanism of $\mathrm{CO}$ and $\mathrm{CO}_{2}$ Hydrogenation to Methanol over Cu-Based Catalysts, ChemCatChem 7 (7) (2015) 1105-1111.

[16] B.J. Lommerts, G.H. Graaf, A.A.C.M. Beenackers, Mathematical modeling of internal mass transport limitations in methanol synthesis, Chemical Engineering Science 55 (23) (2000) 5589-5598.

[17] F. Hayer, et al., Modeling and Simulation of an Integrated Micro Packed Bed Reactor-Heat Exchanger Configuration for Direct Dimethyl Ether Synthesis, Topics in Catalysis 54 (13) (2011) 817-827.

[18] C. Cao, Y. Wang, R.T. Rozmiarek, Heterogeneous reactor model for steam reforming of methane in a microchannel reactor with microstructured catalysts, Catalysis Today 110 (1) (2005) 92-97.

[19] C. Cao, et al., Intensified Fischer-Tropsch synthesis process with microchannel catalytic reactors, Catalysis Today 140 (3) (2009) 149-156.

[20] H. Bakhtiary-Davijany, et al., Analysis of External and Internal Mass Transfer at Low Reynolds Numbers in a Multiple-Slit Packed Bed Microstructured Reactor for Synthesis of Methanol from Syngas, Industrial \& Engineering Chemistry Research 51 (42) (2012) 1357-13579.

[21] F. Dadgar, H.J. Venvik, P. Pfeifer, Application of hot-wire anemometry for experimental investigations of flow distributions in micro-packed bed reactors for synthesis gas conversion, Chemical Engineering Science 177 (2018) 110-121.

[22] K.M.V. Bussche, G.F. Froment, A Steady-State Kinetic Model for Methanol Synthesis and the Water Gas Shift Reaction on a Commecial $\mathrm{Cu} / \mathrm{ZnO} / \mathrm{Al}_{2} \mathrm{O}_{3}$ catalyst, Journal of Catalysis 161 (1) (1996) 1-10.

[23] J. Skrzypek, M. Lachowska, D. Serafin, Methanol synthesis from $\mathrm{CO}_{2}$ and $\mathrm{H}_{2}$ : dependence of equilibrium conversions and exit equilibrium concentrations of components on the main process variables, Chemical Engineering Science 45 (1) (1990) 89-96.

[24] C.Y. Wen, L.-T. Fan, Models for flow systems and chemical reactors, Marcel Dekker, Inc., New York, 1976.

[25] C.L. de Ligny, Coupling between diffusion and convection in radial dispersion of matter by fluid flow through packed beds, Chemical Engineering Science 25 (7) (1970) 1177-1181.

[26] S. Yagi, D. Kunii, Studies on effective thermal conductivities in packed beds, AIChE Journal 3 (3) (1957) 373-381.

[27] G.F. Froment, K.B. Bischoff, Chemical Reactor Analysis and Design, John Wiley and Sons (WIE), 1990.

[28] G.H. Graaf, et al., Intra-particle diffusion limitations in low-pressure methanol synthesis, Chemical Engineering Science 45 (4) (1990) 773-783.

[29] H.H. Kung, Deactivation of methanol synthesis catalysts - a review, Catalysis Today 11 (4) (1992) 443-453.

[30] A. Kölbl, et al., Examination of External Mass Transport in a Microchannel Reactor by Pressure Variation, Chemical Engineering \& Technology 27 (6) (2004) 671-675.

[31] S. Walter, et al., Mass transfer limitations in microchannel reactors, Catalysis Today 110 (1) (2005) 15-25. 


\section{Repository KITopen}

Dies ist ein Postprint/begutachtetes Manuskript.

Empfohlene Zitierung:

Bakhtiary-Davijany, H.; Hayer, F.; Kim Phan, X.; Myrstad, R.; Venvik, H. J.; Pfeifer, P.; Holmen, A.

Modelling and simulation of a single slit micro packed bed reactor for methanol synthesis. 2020. Catalysis today, 343

doi:10.5445/IR/1000096247

Zitierung der Originalveröffentlichung:

Bakhtiary-Davijany, H.; Hayer, F.; Kim Phan, X.; Myrstad, R.; Venvik, H. J.; Pfeifer, P.; Holmen, A.

Modelling and simulation of a single slit micro packed bed reactor for methanol synthesis. 2020. Catalysis today, 343, 226-233.

doi:10.1016/i.cattod.2019.05.026 